\title{
ВИЗНАЧЕННЯ ТЕМПЕРАТУРИ КРИХКОСТІ МОДИФІКОВАНИХ БІТУМІВ ТА ЗМІНИ ЇХ ВЛАСТИВОСТЕЙ ПІСЛЯ ПРОГРІВАННЯ
}

\section{DETERMINATION OF TEMPERATURE OF CRYSTALS OF MODIFIED BITUMES AND CHANGES OF THEIR PROPERTIES AFTER PROGRAMMING}

Талах Л.О., к.т.н., доц., Андрійчук О.В., к.т.н., доц., Шимчук О.П., к.т.н., доц. (Луцький НТУ, м. Луцьк)

Talakh L.O., Ph.D associate professor, Andriichuk O.V., Ph.D. associate professor, Shymchuk O.P., Ph.D. associate professor (Lutsk National Technical University, Lutsk)

Наведено результати експериментальних досліджень температури крихкості та змін властивостей після прогрівання дорожніх бітумів, модифікованих полімерно-активними добавками Kraton D1101, Calprene C-411, Calprene C-501 і восковою добавкою Sasobit.

The temperature of brittleness is the temperature at which bitumen passes from the viscoelastic to the fragile state and in the layer of bitumen, applied to the steel plate and cooled at a constant constant speed, with crackling folds. By its very nature, the degree of fragility to some extent can be regarded as the temperature of the transition of bitumen to vitreous state, in which the viscosity of all amorphous materials is close to $1012 \mathrm{~Pa}$. At the same time, it is believed that the temperature of brittleness is the temperature at which the penetration of different bitumen, having a predominantly "sol" structure, is $1.25 \times 0.1 \mathrm{~mm}$.

When the temperature of the fragility reaches the structure of the bitumen changes qualitatively - the freezing of the components of its high-molecular combinations, the consolidation of Associates asphaltenic complexes, resulting in substantially changing the structural and mechanical properties of bitumen. The value of the temperature of the fragility of the bitumen can predict its behavior and behavior of 
materials based on this bitumen at negative temperatures, that is, the cracking strength of the materials. Such a temperature is an important characteristic when deciding on the use of bitumen in different regions.

In the process of processing the bitumen is exposed to periodic heating. The stability of the composition and properties of bitumen during the heating process is an important technological characteristic that is standardized by the standard. The stability of the properties of bitumen during heating is characterized by: mass change, residual penetration, and softening temperature change. The data of this test give an idea of what happens to the properties of bitumen due to the evaporation of volatile components from it.

To determine the temperature of the fragility of bitumen and modified bitumen and changes in their properties after warming, standard test methods were used.

The results of experimental investigations of the temperature of brittleness and changes in properties after warming of road bitumen, modified with polymeric active additives Kraton D1101, Calprene C411, Calprene C-501 and waxy additive Sasobit are given.

Ключові слова: бітум, модифікований бітум, добавка, температура крихкості, температура спалаху, інтервал пластичності.

Keywords: bitumen, modified bitumen, additive, temperature of the fragility, outbreak temperature, plasticity interval

Температура крихкості - це температура, при якій бітум переходить із в'язкопружного в крихкий стан i в шарі бітуму, нанесеному на сталеву пластину і охолодженому з відповідною постійною швидкістю, при циклічному згині з'являються тріщини. За своєю сутністю температура крихкості в деякій мірі може розглядатись як температура переходу бітуму в склоподібний стан, при якому в'язкість всіх аморфних матеріалів близька до 1012 Па с. В той же час вважається, що температура крихкості $\epsilon$ температурою, при якій пенетрація різних бітумів, що мають переважно структуру «золь», дорівнює $1,25 \times 0,1$ мм.

При досягненні температури крихкості структура бітуму якісно змінюється - заморожується рухомість складових його високомолекулярних сполучень, відбувається ущільнення асоціатів асфальтенових комплексів, в результаті чого суттєво змінюються структурно-механічні властивості бітуму. Значення температури 
крихкості бітуму дозволяе прогнозувати його поведінку та поведінку матеріалів на основі цього бітуму при від'ємних температурах, тобто тріщиностійкість матеріалів. Така температура $\epsilon$ важливою характеристикою при вирішенні питання про застосування бітуму в різних регіонах.

Визначення температури крихкості проводили згідно методик [1]. Для визначення температури крихкості використовували апарат Фраaса. Апарат Фрааса $€$ пристроєм для згинання пластини 3 нанесеним на неї шаром бітуму.

Підготовка до випробувань включала в себе перш за все нанесення бітуму на спеціальні пластині. Чисту пластину довжиною $(41 \pm 0,05)$ мм та шириною 20 мм, товщиною 0,15 мм, виготовлену зі сталевої стрічки 65Г-С-Н-0, $15 \times 20$, промивали бензином i висушували та зважували. Потім на пластину наносили 0,4 г бітуму 3 точністю до 0,01 г. Пластину нагрівали на спеціальному пристрої до тих пір, поки бітум не розтечеться рівномірно по пї поверхні. Пластину укладали на горизонтальну поверхню і швидким рухом палаючого сірника видаляли пухирі повітря, запобігаючи місцевого перегріву. Термін розплавлення та розподілу бітуму складає $6-8$ хв. Пластину 3 бітумом охолоджували на горизонтальній поверхні $20-40$ хв при кімнатній температурі, запобігаючи запилювання. Після цього іiі встановлювали в захвати згинаючого пристрою так, щоб бітумний шар був розташований назовні.

За допомогою охолоджуючого реагенту спирту та вуглекислоти забезпечували зниження температури в приладі зі швидкістю $1^{\circ} \mathrm{C}$ за хвилину. Відхилення, що при цьому допускається, не повинно перевищувати $\pm 1^{\circ} \mathrm{C}$ за 10 хвилин. Починаючи 3 температури приблизно на $10{ }^{\circ} \mathrm{C}$ вище температури крихкості (орієнтовно визначали за показником глибини проникання голки), згинали та розправляли пластину рівномірним обертанням рукоятки 3 частотою 1 оберт за секунду до досягнення найбільшого прогину пластини $(3,5 \pm 0,2)$ мм, а потім в зворотний бік - до досягнення вихідного положення. Повний цикл згинання та випрямлення пластини має закінчуватися за 20-25 с. Аналогічні дії проводили на початку кожної хвилини, досягаючи температури, при якій з'являється перша тріщина, що і свідчить про досягнення крихкого стану. Досліди проводили також з двома іншими пластинами, покритими бітумом. За температуру крихкості приймають середнє арифметичне значення після трьох визначень, округлених до цілого 
числа. Допустиме розходження між визначеннями не повинно перевищувати $3^{\circ} \mathrm{C}$. Результати випробувань подано в табл.1 і на рис. 1.

Таблиця 1

Результати випробувань бітуму на крихкість

\begin{tabular}{|c|c|c|c|c|c|c|}
\hline \multirow[b]{2}{*}{ Склад в'яжучого } & \multirow[b]{2}{*}{ 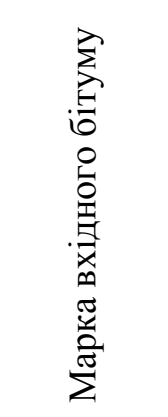 } & \multirow[b]{2}{*}{ 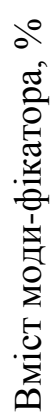 } & \multicolumn{4}{|c|}{$\mathrm{T}_{\text {кр }},{ }^{\circ} \mathrm{C}$} \\
\hline & & & 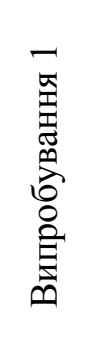 & 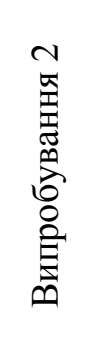 & 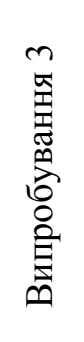 & 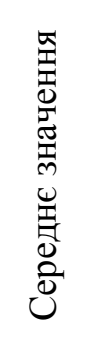 \\
\hline $\begin{array}{c}\text { БФ «Центр ЛТД» } \\
\text { (Кременчуцький } \\
\text { НПЗ) }\end{array}$ & $\begin{array}{c}\text { БНД } \\
90 / 130\end{array}$ & - & -26 & $-25,5$ & -26 & -26 \\
\hline Мозирський НПЗ & БНД 60/90 & - & -26 & -25 & -26 & -26 \\
\hline \multirow{2}{*}{ БНД+КР (Кратон) } & $\begin{array}{c}\text { БНД } \\
90 / 130\end{array}$ & 2 & -25 & $-25,5$ & -24 & -25 \\
\hline & $\begin{array}{c}\text { БНД } \\
90 / 130\end{array}$ & 3 & -28 & $-27,5$ & $-28,5$ & -28 \\
\hline \multirow{2}{*}{$\begin{array}{c}\text { БНД+Calprene } \\
\text { C-411 }\end{array}$} & $\begin{array}{c}\text { БНД } \\
90 / 130\end{array}$ & 2 & $-25,5$ & -26 & $-25,5$ & $-25,5$ \\
\hline & $\begin{array}{c}\text { БНД } \\
90 / 130\end{array}$ & 3 & -28 & $-27,5$ & -29 & -28 \\
\hline \multirow{2}{*}{$\begin{array}{c}\text { БНД+Calprene } \\
\text { C-501 }\end{array}$} & $\begin{array}{c}\text { БНД } \\
90 / 130\end{array}$ & 2 & -26 & $-25,5$ & -25 & $-25,5$ \\
\hline & $\begin{array}{c}\text { БНД } \\
90 / 130\end{array}$ & 3 & $-25,5$ & -24 & -26 & -25 \\
\hline \multirow{2}{*}{ БНД+Sasobit } & $\begin{array}{c}\text { БНД } \\
90 / 130\end{array}$ & 2 & -27 & -27 & -27 & -27 \\
\hline & $\begin{array}{c}\text { БНД } \\
90 / 130\end{array}$ & 3 & -24 & -24 & -24 & -24 \\
\hline
\end{tabular}

У процесі технологічної переробки бітум піддається періодичному нагріву. 
"Сучасні технології та методи розрахунків у будівництві", випуск 11, 2019

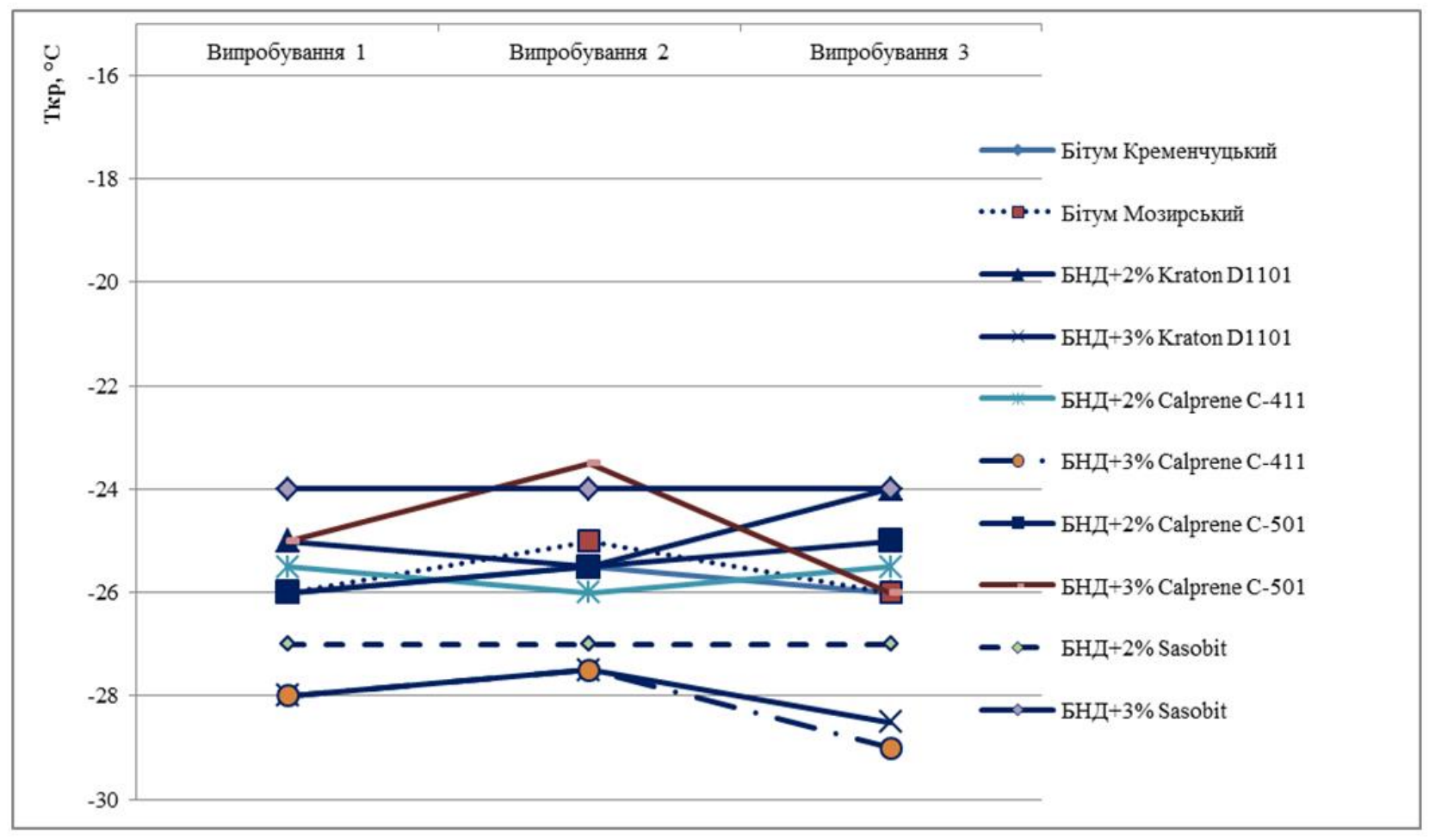

Рис. 1. Залежність між температурою крихкості і вмістом добавки 
Стабільність складу та властивостей бітуму в процесі нагрівання $\epsilon$ важливою технологічною характеристикою, що нормується стандартом. Стабільність властивостей бітуму при нагріванні характеризують: зміною маси, величиною залишкової пенетрації та зміною температури розм'якшення. Дані цього випробування дають уяву про те, що відбувається з властивостями бітуму через випаровування 3 нього летючих компонентів.

Випробування бітумів та модифікованих бітумів проводили згідно методик [2, 3]. Чотири металеві чашки 3 внутрішнім діаметром 128 мм витримували у сушильній шафі при температурі $105 \pm 1{ }^{\circ} \mathrm{C}$ протягом 30 хв. Потім їх охолоджували в ексикаторі та зважували з точністю до 0,01 г. В кожну чашку наливали по $50 \pm 0,1$ г бітуму та, нахиляючи чашку в різні сторони, розподіляли бітум по iï дну рівномірним шаром (приблизно 4 мм). Після охолодження до кімнатної температури в ексикаторі чашки з бітумом зважували 3 точністю до 0,01 г. Зважені чашки 3 бітумом ставили на горизонтальну площу сушильної шафи, попередньо розігрітої до $163{ }^{\circ} \mathrm{C}$. Температуру контролювали термометром, резервуар якого розміщується на рівні чашок. Прогрів бітуму здійснювали протягом 5 годин. При цьому відлік часу починається після того, як у шафі після встановлення чашок буде досягнута температура $163{ }^{\circ} \mathrm{C}$. Як правило, час досягнення цієї температури не повинен перевищувати 15 хв. Після закінчення цього терміну чашки виймали із шафи, ставили в ексикатор і після охолодження до кімнатної температури зважували з точністю до 0,01 г. Зміну маси визначали у відсотках за формулою

$$
X=\frac{m-m_{1}}{m} \cdot 100 \%
$$

де $m$ - маса бітуму до прогріву, $m_{1}-$ маса бітуму після прогріву в г.

За результат випробування приймали середнє арифметичне значення з чотирьох паралельних визначень. Розходження між ними не повинні перевищувати $0,1 \%$.

Для визначення зміни пенетрації після прогріву та температури розм'якшення наважки бітуму з усіх чотирьох чашок розплавляли у шафі при температурі $163^{\circ} \mathrm{C}$, зливали в один посуд, перемішували, а потім використовували для визначення пенетрації та температури розм'якшення згідно з методиками $[4,5]$.

Показники температури спалаху наведено в табл. 2 та рис. 2, а інтервалу пластичності в табл. 3 і рис. 3. 
"Сучасні технології та методи розрахунків у будівництві", випуск 11, 2019

Таблиця 2

Показники температури спалаху $\mathrm{T}_{\text {сп }}{ }^{\circ} \mathrm{C}$ бітумів та модифікованих бітумів

\begin{tabular}{|c|c|c|c|c|c|c|}
\hline \multirow[b]{2}{*}{ Склад в’яжучого } & \multirow[b]{2}{*}{$\begin{array}{c}\text { Марка вхідного } \\
\text { бітуму }\end{array}$} & \multirow{2}{*}{$\begin{array}{c}\text { Вміст } \\
\text { моди- } \\
\text { фікатора, } \\
\text { \% }\end{array}$} & \multicolumn{4}{|c|}{$\mathrm{T}_{\text {сп }},{ }^{\circ} \mathrm{C}$} \\
\hline & & & $\begin{array}{c}\text { Випро- } \\
\text { бування } \\
1\end{array}$ & $\begin{array}{c}\text { Випро- } \\
\text { бування } \\
2\end{array}$ & $\begin{array}{c}\text { Випро- } \\
\text { бування } \\
3\end{array}$ & $\begin{array}{r}\text { 'Середнє } \\
\text { значення }\end{array}$ \\
\hline Кременчуцький НПЗ & БНД 90/130 & - & 234 & 235 & 233 & 234 \\
\hline Мозирський НПЗ & БНД 60/90 & - & 234 & 235 & 235 & 234,7 \\
\hline \multirow{2}{*}{ БНД+КР (Kraton) } & БНД 90/130 & 2 & 236 & 236 & 237 & 236,3 \\
\hline & БНД 90/130 & 3 & 237 & 237 & 237 & 237 \\
\hline \multirow{2}{*}{ БНД+Calprene C-411 } & БНД 90/130 & 2 & 236 & 237 & 236 & 236,3 \\
\hline & БНД 90/130 & 3 & 236 & 236 & 236 & 236 \\
\hline \multirow{2}{*}{ БНД+Calprene C-501 } & БНД 90/130 & 2 & 237 & 236 & 236 & 236,3 \\
\hline & БНД 90/130 & 3 & 237 & 237 & 238 & 237,3 \\
\hline \multirow{2}{*}{ БНД+Sasobit } & БНД 90/130 & 2 & 243 & 242 & 240 & 241,7 \\
\hline & БНД 90/130 & 3 & 246 & 242 & 244 & 244 \\
\hline
\end{tabular}


"Сучасні технології та методи розрахунків у будівництві", випуск 11, 2019

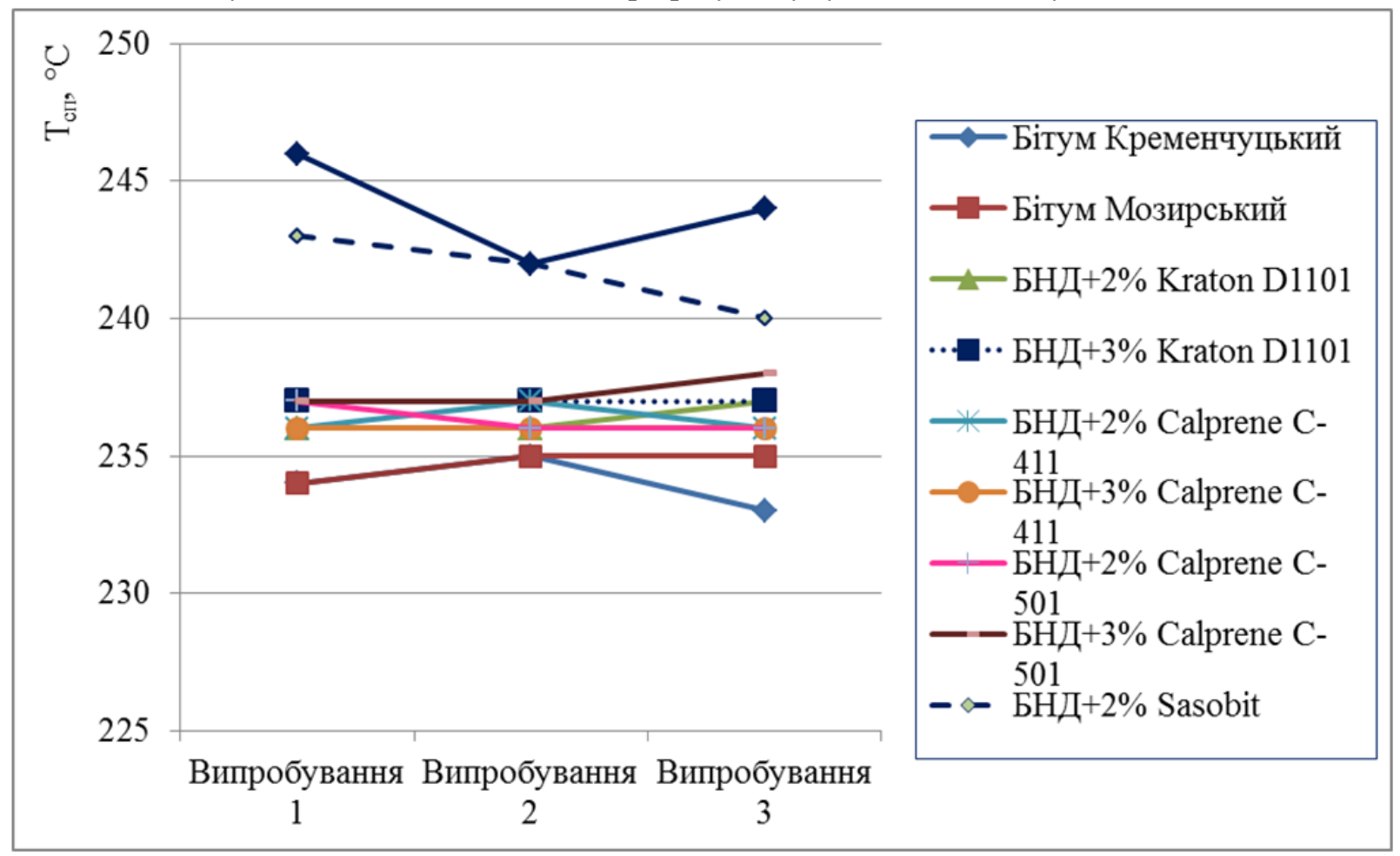

Рис. 2. Залежність між температурою спалаху $\mathrm{T}_{\text {сп }},{ }^{\circ} \mathrm{C}$ і вмістом добавки 
Показники інтервалу пластичності $\boldsymbol{I}$, ${ }^{\circ} \mathrm{C}$ бітумів та модифікованих бітумів

\begin{tabular}{|c|c|c|c|c|c|c|}
\hline \multirow[b]{2}{*}{ Склад в’яжучого } & \multirow{2}{*}{$\begin{array}{c}\text { Марка } \\
\text { вхідного } \\
\text { бітуму }\end{array}$} & \multirow[b]{2}{*}{$\begin{array}{l}\text { Вміст моди- } \\
\text { фікатора, \% }\end{array}$} & \multicolumn{4}{|c|}{$\mathrm{I},{ }^{\circ} \mathrm{C}$} \\
\hline & & & $\begin{array}{c}\text { Випро- } \\
\text { бування } \\
1\end{array}$ & $\begin{array}{c}\text { Випро- } \\
\text { бування } \\
2\end{array}$ & $\begin{array}{c}\text { Випро- } \\
\text { бування } \\
3\end{array}$ & $\begin{array}{l}\text { Середнє } \\
\text { значення }\end{array}$ \\
\hline Кременчуцький НПЗ & БНД 90/130 & - & 69 & 70 & 73 & 70,1 \\
\hline Мозирський НПЗ & БНД 60/90 & - & 69 & 70 & 70 & 69,7 \\
\hline \multirow{2}{*}{ БНД+КР (Kraton) } & БНД 90/130 & 2 & 74 & 73 & 74 & 73,7 \\
\hline & БНД 90/130 & 3 & 80 & 81 & 81,5 & 80,8 \\
\hline \multirow{2}{*}{ БНД+Calprene C-411 } & БНД 90/130 & 2 & 75 & 76 & 76,5 & 75,8 \\
\hline & БНД 90/130 & 3 & 81,5 & 80 & 82,9 & 81,5 \\
\hline \multirow{2}{*}{ БНД+Calprene C-501 } & БНД 90/130 & 2 & 75 & 76 & 78 & 76,3 \\
\hline & БНД 90/130 & 3 & 77,5 & 79 & 78,5 & 78,3 \\
\hline \multirow{2}{*}{ БНД+Sasobit } & БНД 90/130 & 2 & 94 & 91 & 95 & 93,3 \\
\hline & БНД 90/130 & 3 & 104 & 102 & 107 & 104,3 \\
\hline
\end{tabular}


"Сучасні технології та методи розрахунків у будівництві", випуск 11, 2019

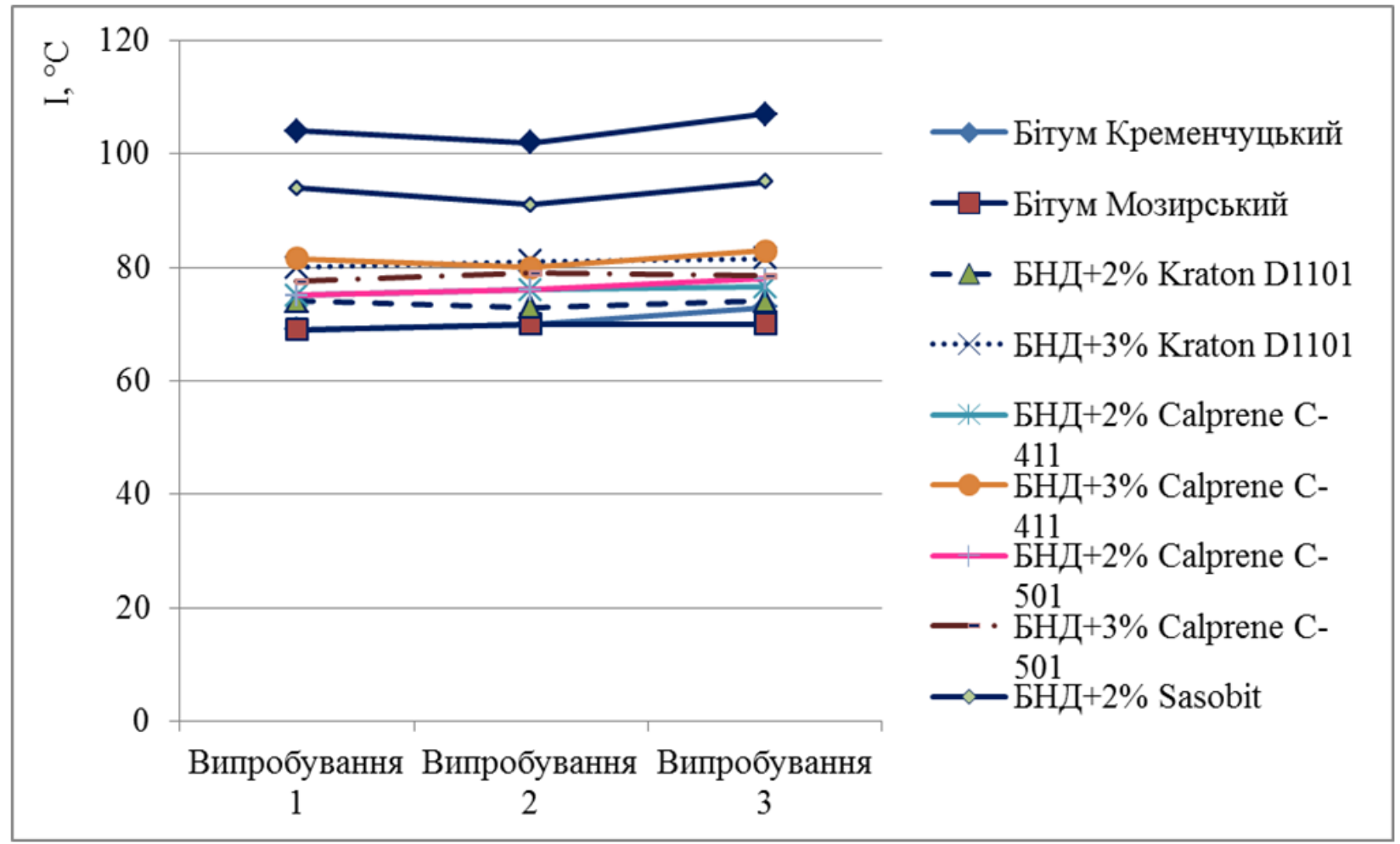

Рис. 3. Залежність інтервалу пластичності $\boldsymbol{I},{ }^{\circ} \mathrm{C}$ від вмісту добавки 


\section{Висновки}

1. Термоеластопласти Calprene C-411 та Calprene C-501, не змінюють або знижують на $1-2^{\circ} \mathrm{C}$ температуру крихкості бітумів.

2. Бітуми модифіковані термоеластопластами Calprene C-411 та Calprene C-501 мають більш широкий інтервал пластичності.

3. Добавка Kraton D1101 у бітуми на $5-7^{\circ} \mathrm{C}$ зменшує температуру крихкості.

4. Воскова добавкою Sasobit. Зміна температури розм'якшення після прогрівання становить $2,5-5^{\circ} \mathrm{C}$, залишкова пенетрація при 25 ${ }^{\circ} \mathrm{C}-75-85 \%$, що знаходиться в межах норм ДСТУ 4044. Після 8 год прогрівання при $180{ }^{\circ} \mathrm{C}$ сумісність бітуму з добавкою Sasobit навіть зростає, що підтверджується збільшенням показників зчеплення та температури розм'якшення при майже незмінних показниках пенетрації.

5. Оптимальна концентрація Sasobit в залежності від вимог до кінцевого продукту знаходиться в межах від 2\% до $3 \%$.

6. Оптимальна концентрація Calprene C-411 складає 2,5-3 \% (в залежності від в'язкості бітуму) та Calprene C-501 не менше 3\%.

7. Calprene C-411 (радіальний) працює більш активно, ніж Calprene C-501 (лінійний) і забезпечує вищу теплостійкість при однаковому вмісті полімерів.

\section{Список використаної літератури}

1. Битумы нефтяные. Метод определения температуры хрупкости по Фраасу (Бітуми нафтові. Метод визначення температури крихкості за Фраасом) - ГОСТ 11507-78. 2. Нефтепродукты. Методы определения температур вспышки и воспламенения в открытом тигле (Нафтопродукти. Методи визначення температур спалаху і займання у відкритому тиглі) - ГОСТ 4333-2014 (ISO 2592:2000). 3. Будівельні матеріали. Бітуми дорожні, модифіковані полімерами. Технічні умови ДСТУ Б В.2.7-135:2007. - К.: Держбуд України, 2007 - 32 с. 4. Битумы нефтяные Метод определения глубины проникания иглы (с Изменениями $\mathrm{N} 1,2,3,4)$ (Бітуми нафтові. Метод визначення глибини проникнення голки) - ГОСТ 11501-78. 5. Битумы нефтяные. Метод определения температуры размягчения по кольцу и шару.) (Бітуми нафтові. Метод визначення температури розм'якшення за кільцем та кулею) - ГОСТ 11506-73*. 